\title{
Solving Large-scale Three-level Linear Fractional Programming Problem with Rough Coefficient in Objective Function
}

\author{
Mohamed Omran \\ Mathematics Department, \\ Sadat Academy, \\ Egypt \\ Laila Abd-Elatif \\ Information Technology \\ Department, Faculty of \\ Computers and \\ Information Systems, \\ Helwan University, Egypt
}

\author{
O. E. Emam \\ Information Systems \\ Department, Faculty of \\ Computers and \\ Information Systems, \\ Helwan University, Egypt. \\ M. Thabet \\ Information System \\ Department, Faculty of \\ Computers and \\ Information Systems, \\ FayoumUniversity, Egypt.
}

\begin{abstract}
In this paper a Large-Scale three level fractional problem is considered with random rough coefficient in objective function, in order to solve this problem, The intervals technique used to convert rough nature in objective into equivalent crisp, Then Tailor Series transformation is used to convert the Large-Scale three level fractional to an equivalent three level linear programming problem, then a Traditional Method used to constructed solution of the three- level programming problem, then we will use Decomposition Technique to solve Large-ScaleProblem. Finally an auxiliary problem is discussed as well as an example is presented.
\end{abstract}

\section{Keywords}

Three-level problem; Fractional Problem; Rough interval Coefficient; Large-Scale; Tailor Series

\section{INTRODUCTION}

Hierarchical optimization or multiple level programming (MLP) techniques are formulated in order to solve decentralized planning problems involving several decision makers (DMs) in a hierarchical organization based on the concept of Stackelberg game theory [1].

Multilevel programming involves optimization problems where the constraint region of the first level problem is implicitly determined by the second level problem and the constrained region of the second level problem is determined by the third level problem, and so on.

During the past few decades, many methodological developments have been reported for multi-level programming problem (MLPP). However, these methods are proven to be computationally ineffective and can handle only simple MLLPs. To overcome the shortcomings of the traditional methods, the concept of membership function of fuzzy set theory was incorporated for large and complex hierarchical optimization problems. Lai [1] at first proposed a new solution concept based on tolerance membership functions as well as multiple objective optimizations to develop an effective fuzzy approach for solving MLPP.
Shih et al. [2] extended Lai's concept and proposed a supervised search procedure by employing non-compensatory max-min aggregation operator for solving MLPP.

Tirayaki [3] discussed interactive compensatory fuzzy programming for decentralized MLLPs to obtain a preferred compensatory compromise Pareto-optimal solution.

Pramanik and Roy [4] developed a fuzzy goal programming (FGP) technique for MLPPs for proper distribution of decision powers to the DMs to reach a satisfying decision.

Baky [5] presented two FGP algorithms to solve multiobjective MLPPs to achieve highest degree of each of the membership goals by minimizing over and under deviational variables. Arbaiy and Watada [5] discussed additive FGP model for solving multi-objective MLPPs for obtaining satisfaction solution.

When the objective functions of level DMs of a MLPP are linear fractional in nature, then the MLPP is called multi-level linear fractional programming problem (MLFPP). Lachhwani and Poonia[6] proposed a different FGP approach for MLFPP by defining separate membership functions for numerator and denominator functions of the fractional objective functions at each level.

\section{PROBLEMFORMULATION AND SOLUTION CONCEPT}

Consider a three-level Large-Scale programming problem of maximization-type with random rough coefficient in the objective function at each level can be written as:

$$
\begin{aligned}
& \operatorname{Max}_{\overline{\mathrm{X}}_{1}} \mathrm{Z}_{1}(\mathrm{x})=\frac{\left[\underline{\mathrm{c}}_{\mathrm{j}}^{\mathrm{L}}, \underline{\mathrm{c}}_{\mathrm{j}}^{\mathrm{U}}\right],\left[\overline{\mathrm{c}}_{\mathrm{j}}^{\mathrm{L}}, \overline{\mathrm{c}}_{\mathrm{j}}^{\mathrm{U}}\right] \mathrm{x}+\alpha_{1}}{\mathrm{~b}_{1} \mathrm{x}+\beta_{1}} \\
& \operatorname{\mathrm {X}}_{2} \mathrm{Z}_{2}(\mathrm{x})=\frac{\left[\underline{\mathrm{b}}_{\mathrm{j}}^{\mathrm{L}}, \underline{\mathrm{b}}_{\mathrm{j}}^{\mathrm{U}}\right],\left[\overline{\mathrm{b}}_{\mathrm{j}}^{\mathrm{L}}, \overline{\mathrm{b}}_{\mathrm{j}}^{\mathrm{U}}\right] \mathrm{x}+\alpha_{2}}{\mathrm{~b}_{2} \mathrm{x}+\beta_{2}} \\
& \operatorname{Max}_{\overline{\mathrm{X}}_{3}} \mathrm{Z}_{3}(\mathrm{x})=\frac{\left[\underline{a}_{\mathrm{j}}^{\mathrm{L}}, \underline{\mathrm{a}}_{\mathrm{j}}^{\mathrm{U}}\right],\left[\overline{\mathrm{a}}_{\mathrm{j}}^{\mathrm{L}}, \overline{\mathrm{a}}_{\mathrm{j}}^{\mathrm{U}}\right] \mathrm{x}+\alpha_{3}}{\mathrm{~b}_{3} \mathrm{x}+\beta_{3}}
\end{aligned}
$$


Subject to

$\mathrm{x} \in \mathrm{s}=\left\{\mathrm{A}_{1} \mathrm{x}_{1}+\mathrm{A}_{2} \mathrm{x}_{2}+\cdots+\mathrm{A}_{\mathrm{j}} \mathrm{x}_{\mathrm{j}}(\geq,=, \leq) \mathrm{B}, \mathrm{x} \geq 0\right\}$.

Here $S$ is the multilevel convex constraints set and $\mathrm{Z}_{1}, \mathrm{Z}_{1}$ and $\mathrm{Z}_{3}$ are the objective functions of the first level decision maker (FLDM), second level decision maker (SDLM) and third level decision maker (TLDM), $\left[\underline{c}_{j}^{\mathrm{L}}, \underline{\mathrm{c}}_{\mathrm{j}}^{\mathrm{U}}\right],\left[\overline{\mathrm{c}}_{j}^{\mathrm{L}}, \overline{\mathrm{c}}_{\mathrm{j}}^{\mathrm{U}}\right],\left[\underline{b}_{j}^{\mathrm{L}}, \underline{\mathrm{b}}_{\mathrm{j}}^{\mathrm{U}}\right],\left[\overline{\mathrm{b}}_{\mathrm{j}}^{\mathrm{L}}, \overline{\mathrm{b}}_{\mathrm{j}}^{\mathrm{U}}\right],\left[\underline{\mathrm{a}}_{\mathrm{j}}^{\mathrm{L}}, \underline{\mathrm{a}}_{\mathrm{j}}^{\mathrm{U}}\right],\left[\overline{\mathrm{a}}_{\mathrm{j}}^{\mathrm{L}}, \overline{\mathrm{a}}_{\mathrm{j}}^{\mathrm{U}}\right]$ are rough intervals coefficient of the objective function for the three levels. Also let $(\mathrm{j}=1,2, \ldots, \mathrm{n}), \mathrm{x}=\left(\mathrm{x}_{1}, \mathrm{x}_{2}, \ldots, \mathrm{x}_{\mathrm{n}}\right)$ denote the vector of all decision variables.

To tackle problem (1)-(4) and to deal with rough nature in (TLPP) the problem is transformed using the Intervals method to transform the rough coefficient in objective function into crisp number presented in the following section .

\section{THE EQUIVALENT CRISP MODEL FOR THREE-LEVEL LINEAR PROBLEM WITH ROUGH IN OBJECTIVE FUNCTION}

Conversion of (TLPP) with rough coefficient in objective number into upper and lower approximation is usually a hard work for many cases, but transformation process needs to know the following definitions:

\section{Definition 3.1:}

Rough Interval (RI) can be considered as a qualitative value from vague concept defined on a variable xin $R$.

\section{Definition 3.2:}

The qualitative value $A$ is called a rough interval when one can assign two closed intervals $\mathrm{A} *$ and $\mathrm{A} *$ on $\mathrm{R}$ to it where $\mathrm{A} * \subseteq \mathrm{A} *$.

\section{Definition 3.3:}

$\mathrm{A} *$ and $\mathrm{A} *$ are called the lower approximation interval (LAI) and the upper approximation interval (UAI) of $\mathrm{A}$, respectively. Further, $\mathrm{A}$ is denoted by $\mathrm{A}=(\mathrm{A} *$ and $\mathrm{A} *)$.

\section{Definition 3.4:}

if the Problem (3.1) has qi $(i=1, \ldots, m)$ qi rough coefficients in right and/or left hand sides and q0 rough coefficients in the objective function, then there exist $2 \mathrm{Q}$ corresponding Linear problem with interval coefficient (LPIC) problems and $4 Q$ corresponding LP problems where $\mathrm{Q}=\mathrm{q} 0 \times \mathrm{q} 1 \times \ldots \times$ qm.

\section{Definition 3.5:}

Consider all of the corresponding LPIC problems and LP problems of Problem (3.1).

The interval $\left[\mathrm{Z}_{*}^{\mathrm{l}}, \mathrm{Z}_{*}^{\mathrm{u}}\right]\left(\left[\mathrm{Z}^{* 1}, \mathrm{Z}^{* \mathrm{u}}\right]\right)$ is called the surely optimal range of problem (3.1), if the optimal range of each LPIC problem is a superset of $\left[\mathrm{Z}_{*}^{\mathrm{l}}, \mathrm{Z}_{*}^{\mathrm{u}}\right]\left(\left[\mathrm{Z}^{* 1}, \mathrm{Z}^{* \mathrm{u}}\right]\right)$.

Let $\left[\mathrm{Z}_{*}^{1}, \mathrm{Z}_{*}^{\mathrm{u}}\right]\left(\left[\mathrm{Z}^{* 1}, \mathrm{Z}^{* \mathrm{u}}\right]\right)$ be surely optimal range of problem (4.1).then the rough interval $\left(\left[\mathrm{Z}_{*}^{\mathrm{l}}, \mathrm{Z}_{*}^{\mathrm{u}}\right]\left(\left[\mathrm{Z}^{* 1}, \mathrm{Z}^{* \mathrm{u}}\right]\right)\right.$ is called the rough optimal range of problem (3.1).

The optimal solution of each corresponding LP problem of the problem (4.1) which its optimal value belongs to $\left[\mathrm{Z}_{*}^{\mathrm{l}}, \mathrm{Z}_{*}^{\mathrm{u}}\right]\left(\left[\mathrm{Z}^{* \mathrm{l}}, \mathrm{Z}^{* \mathrm{u}}\right]\right)$ is called a completely satisfactory solution of the problem (3.1).
Now, the equivalent problem of the first level with rough coefficient in objective function by using Intervals method can obtained by getting the surely optimal range of LPIC problem (4.1) by solving two classical LPs as Follow:

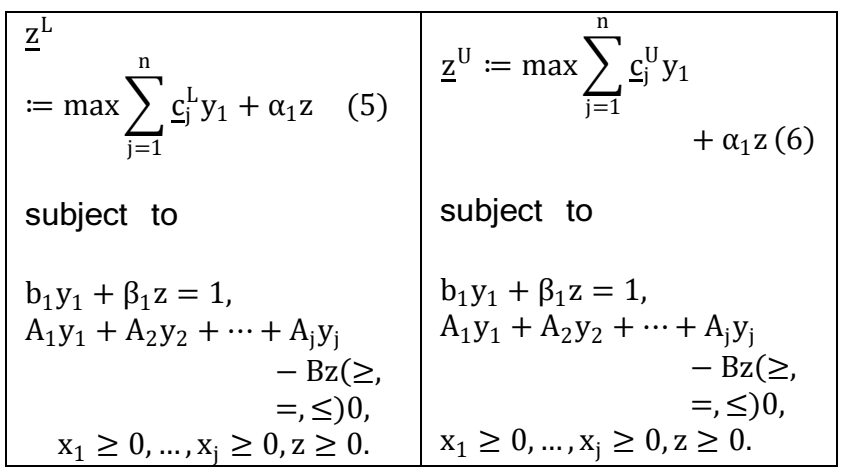

While the possibly optimal range of LPIC Problem (4.1) can be obtained by solving two classical LPs as follows:

\begin{tabular}{|c|c|}
\hline $\begin{array}{l}\overline{\mathrm{z}}^{\mathrm{L}}:=\max \sum_{\mathrm{j}=1}^{\mathrm{n}} \bar{c}_{\mathrm{j}}^{\mathrm{L}} \mathrm{y}_{1}+\alpha_{1} \mathrm{z}(7) \\
\text { subject to } \\
\begin{array}{r}\mathrm{b}_{1} \mathrm{y}_{1}+\beta_{1} \mathrm{z}=1, \\
\mathrm{~A}_{1} \mathrm{y}_{1}+\mathrm{A}_{2} \mathrm{y}_{2}+\cdots+\mathrm{A}_{\mathrm{j}} \mathrm{y}_{\mathrm{j}} \\
\qquad \quad \mathrm{Bz}(\geq \\
\quad=, \leq) 0 \\
\mathrm{x}_{1} \geq 0, \ldots, \mathrm{x}_{\mathrm{j}} \geq 0, \mathrm{z} \geq 0\end{array}\end{array}$ & $\begin{array}{l}\overline{\mathrm{z}}^{\mathrm{U}} \\
\begin{array}{r}:=\max \sum_{\mathrm{j}=1}^{\mathrm{n}} \overline{\mathrm{c}}_{\mathrm{j}}^{\mathrm{U}} \mathrm{y}_{1}+\alpha_{1} \mathrm{z}(8) \\
\text { subject to } \\
\begin{array}{r}\mathrm{b}_{1} \mathrm{y}_{1}+\beta_{1} \mathrm{z}=1, \\
\mathrm{~A}_{1} \mathrm{y}_{1}+\mathrm{A}_{2} \mathrm{y}_{2}+\cdots+\mathrm{A}_{\mathrm{j}} \mathrm{y}_{\mathrm{j}} \\
\quad-\mathrm{Bz}(\geq, \\
=, \leq) 0,\end{array} \\
\begin{array}{r}\mathrm{x}_{1} \geq 0, \ldots, \mathrm{x}_{\mathrm{j}} \geq 0, \mathrm{z} \geq 0 .\end{array}\end{array}\end{array}$ \\
\hline
\end{tabular}

After using intervals method to convert problem (4.1) for the first level from rough nature to crisp, that resulted in four multi-level programming problems. These steps will be repeated for second and third level, so the problem of (TLFPP) converted into twelve linear problems with four problems at each level.

Then each level has hislher own optimal solution. To deal with the conflict between the solutions, the fuzzy approach is used.

\section{DECOMPOSITION ALGORITHM FOR SOLVING A THREE LEVEL LARGE SCALE LINEAR PROGRAMMING PROBLEM}

The three level large scale linear programming problem is solved by adopting the leader-follower Stackelberg strategy combine with Dantzig and Wolf decomposition method $[7,8,9]$.

One first gets the optimal solution that is acceptable to FLDM using the decomposition method to break the large scale problem into n-sub problems that can be solved directly.

The decomposition principle is based on representing the TLLSLPP in terms of the extreme points of the sets $d_{j} x_{j} \leq b_{j}, x_{j} \geq 0, j=1,2, . ., m$. To do so, the solution space described by each $d_{j} x_{j} \leq b_{j}, x_{j} \geq 0$, $j=1,2, . ., m$ must be bounded and closed, for more details see. 
Then by inserting the FLDM decision variable to the SLDM for him/her to seek the optimal solution using Dantzig and Wolf decomposition method [10] then the decomposition method break the large scale problem into $n$-sub problems that can be solved directly.

Finally the TLDM do the same action till he obtains the optimal solution of his problem which is the optimal solution to TLLSLPP.

\subsection{The First-Level Decision-Maker (FLDM) Problem}

The first-level decision-maker problem of the TLLSLPP is as follows:

[First Level]

$\operatorname{Max} F_{1}(x)=\operatorname{Max} \sum_{j=1}^{m} c_{1 j} x_{j}$,

Subject to

$x \in G$.

To obtain the optimal solution of the SLDM problem; the SLDM solves his master problem by the decomposition method [10] as the FLDM.

\subsection{The Second-Level Decision-Maker} (SLDM) Problem

Secondly, according to the mechanism of theTLLSLPP, the FLDM variables $x_{1}^{F}, x_{2}^{F}$ must be given to the SLDM; hence, the SLDM problem of the (TLLSLPPFN) can be written as follows:

[Second Level]

$\operatorname{Max} F_{2}(x)=\operatorname{Max} \sum_{j=1}^{m} c_{2 j} x_{j}$

Subject to

$x \in G_{2}$.

Where

$$
G_{2}=\left(x_{1}^{F}, x_{2}^{F}, \ldots, x_{m}\right) .
$$

To obtain the optimal solution of the SLDM problem; the SLDM solves his master problem by the decomposition method [10] as the FLDM.

\subsection{The Third-Level Decision-Maker (TLDM) Problem}

Finally, according to the mechanism of the TLLSLPP, the SLDM variables $x_{1}^{F}, x_{2}^{F}, x_{3}^{S}, x_{4}^{S}$ must be given to the TLDM; hence, the TLDM problem can be written as follow:

[Third Level]

$\operatorname{Max} F_{3}(x)=\operatorname{Max} \sum_{j=1}^{m} c_{3 j} x_{j}$

Subject to

$$
x \in G_{3} .
$$

Where

$$
G_{3}=\left(x_{1}^{F}, x_{2}^{F}, x_{3}^{S}, x_{4}^{S}, \ldots, x_{m}\right) .
$$

To obtain the optimal solution of the TLDM problem; the TLDM solves his master problem by the decomposition method [10] as the FLDM and SLDM.

Now the optimal solution $\left(x_{1}^{F}, x_{2}^{F}, x_{3}^{S}, x_{4}^{S}, x_{5}^{T}, x_{6}^{T}, \ldots, x_{m}^{T}\right)$ of the TLDM is the optimal solution of the TLLSLPP.

\section{NUMERICAL EXAMPLE} First level:

$\mathrm{P} 1=\max (X 1 X 2)=\frac{11 \mathrm{x}_{1}+3 \mathrm{x}_{2}+4 \mathrm{x}_{5}}{\mathrm{x}_{1}+4 \mathrm{x}_{2}+6}$
$\mathrm{P} 2=\max (X 1 X 2)=\frac{15 \mathrm{x}_{1}+6 \mathrm{x}_{2}+9 \mathrm{x}_{5}+4 \mathrm{x}_{6}}{\mathrm{x}_{1}+4 \mathrm{x}_{2}+6}$
$\mathrm{P} 3=\max (\mathrm{X} 1 \mathrm{X} 2)=\frac{12 \mathrm{x}_{1}+2 \mathrm{x}_{2}+5 \mathrm{x}_{5}+2 \mathrm{x}_{6}}{\mathrm{x}_{1}+4 \mathrm{x}_{2}+6}$
$\mathrm{P} 3=\max (X 1 X 2)=\frac{14 \mathrm{x}_{1}+5 \mathrm{x}_{2}+7 \mathrm{x}_{5}+3 \mathrm{x}_{6}}{\mathrm{x}_{1}+4 \mathrm{x}_{2}+6}$

Subject To:

$\mathrm{X} 1+\mathrm{X} 2+\mathrm{X} 3+\mathrm{X} 4+\mathrm{X} 5+\mathrm{X} 6 \leq 10$

$\mathrm{X} 1+\mathrm{X} 2 \leq 3$

$\mathrm{X} 3+2 \mathrm{X} 4 \leq 4$

$\mathrm{X} 5+\frac{1}{3} \mathrm{X} 6 \leq 3$

$\mathrm{X} 1, \mathrm{X} 2, \mathrm{X} 3, \mathrm{X} 4, \mathrm{X} 5, \mathrm{X} 6 \geq 0$

Solving by applying tailor series to convert production objectives function to linear Function

$\mathrm{P} 1=$ MAX 0.85X1-0.32X2+0.36X5+0.74

$\mathrm{P} 2=\mathrm{MAX} 1.08 \mathrm{X} 1-0.57 \mathrm{X} 2+0.81 \mathrm{X} 5+0.36 \mathrm{X} 6+1.41$

$\mathrm{P} 3=\mathrm{MAX} 1.08 \mathrm{X} 1-0.39 \mathrm{X} 2+0.45 \times 5+0.27 \mathrm{X} 6+.68$

$\mathrm{P}=$ MAX 1.03X1-0.50X2+0.63X5+0.27X6+1.2

Solving by applying Decomposition Algorithm

\begin{tabular}{|c|c|c|c|c|c|c|}
\hline $\mathrm{X} 6$ & $\mathrm{X} 5$ & $\mathrm{X} 4$ & $\mathrm{X} 3$ & $\mathrm{X} 2$ & $\mathrm{X} 1$ & P1 \\
\hline 0 & 3 & 0 & 0 & 0 & 3 & 4.37 \\
\hline $\mathrm{X} 6$ & $\mathrm{X} 5$ & $\mathrm{X} 4$ & $\mathrm{X} 3$ & $\mathrm{X} 2$ & $\mathrm{X} 1$ & $\mathrm{P} 2$ \\
\hline 5.97 & 1.02 & 0 & 0 & 0 & 3 & 7.633 \\
\hline $\mathrm{X} 6$ & $\mathrm{X} 5$ & $\mathrm{X} 4$ & $\mathrm{X} 3$ & $\mathrm{X} 2$ & $\mathrm{X} 1$ & P3 \\
\hline 5.99 & 1.02 & 0 & 0 & 0 & 3 & 5.99 \\
\hline $\mathrm{X} 6$ & $\mathrm{X} 5$ & $\mathrm{X} 4$ & $\mathrm{X} 3$ & $\mathrm{X} 2$ & $\mathrm{X} 1$ & $\mathbf{P 4}$ \\
\hline 5.97 & 1.02 & 0 & 0 & 0 & 3 & 6.55 \\
\hline
\end{tabular}

Second Level

Upper

$$
\begin{aligned}
& \mathrm{P} 1=\frac{3 \mathrm{x}_{3}+4 \mathrm{x}_{4}+\mathrm{x}_{5}+\mathrm{x}_{6}}{6 \mathrm{x}_{3}+4 \mathrm{x}_{4}+2} \\
& \mathrm{P} 2=\frac{6 \mathrm{x}_{3}+4 \mathrm{x}_{4}+4 \mathrm{x}_{5}+\mathrm{x}_{6}}{6 \mathrm{x}_{3}+4 \mathrm{x}_{4}+2}
\end{aligned}
$$


Lower

$$
\begin{aligned}
& P 3=\frac{4 x_{3}+5 x_{4}+2 x_{5}+x_{6}}{6 x_{3}+4 x_{4}+2} \\
& P 4=\frac{5 x_{3}+7 x_{4}+3 x_{5}+x_{6}}{6 x_{3}+4 x_{4}+2}
\end{aligned}
$$

Subject To:

$\mathrm{X} 1+\mathrm{X} 2+\mathrm{X} 3+\mathrm{X} 4+\mathrm{X} 5+\mathrm{X} 6 \leq 10$

$\mathrm{X} 1+\mathrm{X} 2 \leq 3$

$\mathrm{X} 3+2 \mathrm{X} 4 \leq 4$

$\mathrm{X} 5+\frac{1}{3} \mathrm{X} 6 \leq 3$

$\mathrm{X} 1, \mathrm{X} 2, \mathrm{X} 3, \mathrm{X} 4, \mathrm{X} 5, \mathrm{X} 6 \geq 0$

Solving by applying tailor series to convert production objectives function to linear Function

$\mathrm{P} 1=\mathrm{MAX}-.125 \mathrm{X} 3+0.083 \mathrm{X} 4+0.083 \mathrm{X} 5+0.083 \mathrm{X} 6+.626$

$\mathrm{P} 2=$ MAX $-.125 \mathrm{X} 3-0.083 \mathrm{X} 4+0.166 \mathrm{X} 5+0.083 \mathrm{X} 6+1.209$

$\mathrm{P} 3=\mathrm{MAX}-.166 \mathrm{X} 3+0.083 \mathrm{X} 4+0.166 \mathrm{X} 5+0.083 \mathrm{X} 6+0.834$

$\mathrm{P} 4=\mathrm{MAX}-.25 \mathrm{X} 3+0.138 \mathrm{X} 4+0.25 \times 5+0.083 \times 6+1.109$

Solving by applying Decomposition Algorithm Given $\underline{X 1, X 2 \text { from first level }}$

\begin{tabular}{|l|l|l|l|l|l|l|}
\hline $\mathrm{X} 6$ & $\mathrm{X} 5$ & $\mathrm{X} 4$ & $\mathrm{X} 3$ & $\mathrm{X} 2$ & $\mathrm{X} 1$ & $\mathrm{P} 1$ \\
\hline 2.98 & 2.014 & 2 & 0 & 0 & 0 & 1.207 \\
\hline $\mathrm{X} 6$ & $\mathrm{X} 5$ & $\mathrm{X} 4$ & $\mathrm{X} 3$ & $\mathrm{X} 2$ & $\mathrm{X} 1$ & $\mathrm{P} 2$ \\
\hline 5.970 & 1.029 & 0 & 0 & 0 & 0 & 1.875 \\
\hline $\mathrm{X} 6$ & $\mathrm{X} 5$ & $\mathrm{X} 4$ & $\mathrm{X} 3$ & $\mathrm{X} 2$ & $\mathrm{X} 1$ & $\mathrm{P} 3$ \\
\hline 2.98 & 2.014 & 2 & 0 & 0 & 0 & 1.58 \\
\hline $\mathrm{X} 6$ & $\mathrm{X} 5$ & $\mathrm{X} 4$ & $\mathrm{X} 3$ & $\mathrm{X} 2$ & $\mathrm{X} 1$ & $\mathrm{P} 4$ \\
\hline 2.985 & 2.014 & 2 & 0 & 0 & 0 & 2.136 \\
\hline
\end{tabular}

Solving by applying DecompositionAlgorithm in isolation from first level

\begin{tabular}{|l|l|l|l|l|l|l|}
\hline $\mathrm{X} 6$ & $\mathrm{X} 5$ & $\mathrm{X} 4$ & $\mathrm{X} 3$ & $\mathrm{X} 2$ & $\mathrm{X} 1$ & $\mathrm{P} 1$ \\
\hline 7.462 & .537 & 2 & 0 & 0 & 0 & 1.456 \\
\hline $\mathrm{X} 6$ & $\mathrm{X} 5$ & $\mathrm{X} 4$ & $\mathrm{X} 3$ & $\mathrm{X} 2$ & $\mathrm{X} 1$ & $\mathrm{P} 2$ \\
\hline 9.090 & 0 & 0 & 0 & 0 & 0 & 1.963 \\
\hline $\mathrm{X} 6$ & $\mathrm{X} 5$ & $\mathrm{X} 4$ & $\mathrm{X} 3$ & $\mathrm{X} 2$ & $\mathrm{X} 1$ & $\mathrm{P} 3$ \\
\hline 7.462 & .537 & 2 & 0 & 0 & 0 & 1.708 \\
\hline
\end{tabular}

\section{Third Level}

Upper

$$
\begin{array}{r}
P 1=\frac{x_{1}+x_{5}+4 x_{6}}{x_{5}+x_{6}+6} \\
P 2=\frac{x_{1}+4 x_{5}+9 x_{6}}{x_{5}+x_{6}+6}
\end{array}
$$

Lower

$$
\begin{aligned}
& \text { P3 }=\frac{x_{1}+2 x_{5}+5 x_{6}}{x_{5}+x_{6}+6} \\
& \text { P4 }=\frac{x_{1}+3 x_{5}+7 x_{6}}{x_{5}+x_{6}+6}
\end{aligned}
$$

Subject to

$x_{1}+x_{2}+x_{3}+x_{4}+x_{3}+x_{4} \geq 10$,

$x_{1}+x_{2} \leq 3$

$x_{3}+2 x_{4} \leq 4$

$x_{5}+1 / 3 x_{6} \leq 3$,

$x_{1} \geq 0, x_{2} \geq 0, x_{3} \geq 0, x_{4} \geq 0, x_{5} \geq 0, x_{6} \geq 0$,

Solving by applying tailor series to convert production objectives function to linear Function

$\mathrm{P} 1=\operatorname{MAX} 0.125 \mathrm{X} 1+0.218 \mathrm{X} 5+0.593 \mathrm{X} 6-0.186$

$\mathrm{P} 2=$ MAX $0.125 \times 1+0.718 \times 5+1.343 \times 6-0.436$

$\mathrm{P} 3=\mathrm{MAX} 0.125 \mathrm{X} 1+0.375 \mathrm{X} 5+0.75 \mathrm{X} 6-1.125$

$\mathrm{P} 4=$ MAX $0.125 X 1+0.546 \times 5+1.046 \times 6-0.342$

Solving by applying Decomposition Algorithm Given $\underline{X 1, X 2 \text { from first level and X3,X4 from Level } 2}$

\begin{tabular}{|l|l|l|l|l|l|l|}
\hline $\mathrm{X} 6$ & $\mathrm{X} 5$ & $\mathrm{X} 4$ & $\mathrm{X} 3$ & $\mathrm{X} 2$ & $\mathrm{X} 1$ & $\mathrm{P} 1$ \\
\hline 5 & 0 & 0 & 0 & 0 & 0 & 3.154 \\
\hline $\mathrm{X} 6$ & $\mathrm{X} 5$ & $\mathrm{X} 4$ & $\mathrm{X} 3$ & $\mathrm{X} 2$ & $\mathrm{X} 1$ & $\mathrm{P} 2$ \\
\hline 7 & 0 & 0 & 0 & 0 & 0 & 9.30 \\
\hline $\mathrm{X} 6$ & $\mathrm{X} 5$ & $\mathrm{X} 4$ & $\mathrm{X} 3$ & $\mathrm{X} 2$ & $\mathrm{X} 1$ & $\mathrm{P} 3$ \\
\hline 5 & 0 & 0 & 0 & 0 & 0 & 3 \\
\hline $\mathrm{X} 6$ & $\mathrm{X} 5$ & $\mathrm{X} 4$ & $\mathrm{X} 3$ & $\mathrm{X} 2$ & $\mathrm{X} 1$ & $\mathrm{P} 4$ \\
\hline 5 & 0 & 0 & 0 & 0 & 0 & 5.263 \\
\hline
\end{tabular}


Solving by applying Decomposition Algorithm in isolation from first level and second level

\begin{tabular}{|l|l|l|l|l|l|l|}
\hline $\mathrm{X} 6$ & $\mathrm{X} 5$ & $\mathrm{X} 4$ & $\mathrm{X} 3$ & $\mathrm{X} 2$ & $\mathrm{X} 1$ & $\mathrm{P} 1$ \\
\hline 9.090 & 0 & 0 & 0 & 0 & $\begin{array}{l}0.90 \\
90\end{array}$ & 5.318 \\
\hline $\mathrm{X} 6$ & $\mathrm{X} 5$ & $\mathrm{X} 4$ & $\mathrm{X} 3$ & $\mathrm{X} 2$ & $\mathrm{X} 1$ & $\mathrm{P} 2$ \\
\hline 9.090 & 0 & 0 & 0 & 0 & $\begin{array}{l}0.90 \\
90\end{array}$ & 11.886 \\
\hline $\mathrm{X6}$ & $\mathrm{X} 5$ & $\mathrm{X} 4$ & $\mathrm{X} 3$ & $\mathrm{X} 2$ & $\mathrm{X} 1$ & $\mathrm{P} 3$ \\
\hline 9.090 & 0 & 0 & 0 & 0 & $\begin{array}{l}0.90 \\
90\end{array}$ & 5.806 \\
\hline $\mathrm{X6}$ & $\mathrm{X} 5$ & $\mathrm{X} 4$ & $\mathrm{X} 3$ & $\mathrm{X} 2$ & $\mathrm{X} 1$ & $\mathrm{P} 4$ \\
\hline 9.090 & 0 & 0 & 0 & 0 & $\begin{array}{l}0.90 \\
90\end{array}$ & 9.280 \\
\hline
\end{tabular}

\section{CONCLUSION}

This paper presents a solving method for a three level fractional problem with a rough coefficient in the objective function, we first began by converting the rough nature of the problem into its equivalent crisp problem by using interval method then converting Fractional using Tailor series finally solving the three level problem using the compromised approach.

\section{REFERENCES}

[1] Y. J. Lai, "Hierarchical optimization: a satisfactory solution," Fuzzy Sets and Systems, Vol. 77 No. 3, (1996), pp. 321-335.

[2] M. Osman, M. Abo-Sinna, A. Amer , O. Emam, "A multi-level non-linear multi-objective decision-making under fuzziness", applied mathematics and computation. 153, ( 2004),pp.239-252.

[3] P. Kundu, S. Kar, M. Maiti, "Some Solid transportation Model with Crisp and Rough Costs", World Academy of Science, Engineering and Technology, vol. 73, (2013),pp. 185-192.

[4] S. Pramanik, and T. K. Roy, "Fuzzy goal programming approach to multi-level programming problems," European Journal of Operational Research, Vol. 176 (2), (2007), pp.1151-1166.

[5] N. Arbaiy, and J. Watada, "Fuzzy goal programming for multi-level multi-objective problem: an additive model," Software Engineering and Computer Systems Communication in Computer and Information Sci-ence, Vol. 180, (2011), pp. 81-95.

[6] K. Lachhwani, and M. P. Poonia, Mathematical solution of multilevel fractional programming problem with fuzzy goal programming approach, Journal of Industrial Engineering International, Vol. 8, No. 16,(2012), pp. 111

[7] M.A. Abo-sinna, and Abou - El- Enin, An interactive algorithm for large scale multiple objective programming problems with fuzzy parameters through TOPSIS approach , Yugoslav Journal of Operations Research, (21) (2011), 253273

[8] G. Dantzig, and P. Wolfe, The decomposition algorithm for linear programs Econometrica, Econometrics, 9 (4) (1961), 767-778.

[9] A. A. El-Sawy, N. A. El-khouly, and T. H. M. Abou - ElEnin, An algorithm for decomposing the parametric space in large scale linear vector optimization problems : A fuzzy approach ,AMSE, Advances in Modeling \&Analysis, 55 (2) (2000), 1-16.

[10] T. I. Sultan, O. E. Emam and A. A. Abohany, A decomposition algorithm for solving a three-level large scale linear programming problem, Applied Mathematics and Information Science, 5 (Sep. 2014), 2217- 2223 